\title{
Research Square \\ The Prevalence of Drug-Resistant-epilepsy and its Associated Factors in Patients with Epilepsy
}

Parisa Mohammadzadeh

Urmia University of Medical Sciences

Surena Nazarbaghi ( $\nabla$ kavak_22rama@yahoo.com )

Urmia University of Medical Sciences

\section{Research Article}

Keywords: Drug-resistant-epilepsy, Epilepsy, Seizure

Posted Date: January 8th, 2021

DOI: https://doi.org/10.21203/rs.3.rs-137800/v1

License: (9) This work is licensed under a Creative Commons Attribution 4.0 International License. Read Full License

Version of Record: A version of this preprint was published at Clinical Neurology and Neurosurgery on December 1st, 2021. See the published version at https://doi.org/10.1016/j.clineuro.2021.107086. 


\section{Abstract}

Background: Drug-resistant-epilepsy (DRE) is a major challenge in adult patients with epilepsy. The majority of previous studies evaluating the risk factors of DRE have been conducted in children. Therefore, this study aimed to investigate the prevalence of DRE and its associated factors in adults.

Methods: All patients aged over 12 years with an established diagnosis of epilepsy since at least one year before the admission who were admitted with seizure to the neurology ward of a tertiary care hospital were consecutively included from 20th March 2014 to 19th March 2020. Patients were classified into two groups of DRE and non-DRE groups. The archived-files of the patients were retrospectively reviewed and the data were extracted and recorded in a pre-prepared checklist.

Results: A total of 436 patients were investigated. The most common causes of epilepsy were idiopathic (53.9\%), vascular (22.5\%), and CP/developmental disorders (8.3\%). There was no significant difference between DRE and non-DRE patients in terms of age, sex, seizure type (generalized/partial). Vascular causes were more prevalent in the non-DRE group, and idiopathic, post-traumatic/surgery,

$\mathrm{MS} /$ degenerative, poor compliance, $\mathrm{CP} /$ developmental disorders, and space-occupying lesions were more prevalent in the DRE group. In multivariate regression analysis only the presence of $\mathrm{CP} /$ developmental disorders was independently associated with a higher probability of DRE (adjusted OR $=2.170,95 \% \mathrm{Cl}=$ 1.017 to $4.633, p=0.045)$.

Conclusion: The prevalence of DRE is still considerably high. Therefore, considering its serious consequences, more investigations should be carried out to determine proper strategies for reducing its incidence. We found the history of $\mathrm{CP} /$ developmental disorders to be independently associated with DRE. Therefore, perinatal care to reduce the incidence of $\mathrm{CP} /$ developmental disorders and encouraging these patients to use their medications accurately may be helpful.

\section{Introduction}

Epilepsy affects 65 million people worldwide, almost $80 \%$ of whom live in developing countries [1, 2]. Meta-analysis studies on the incidence of epilepsy indicate that the incidence in developing countries and developed countries is on average 67.8 / 100,000 and 43.4 / 100,000, respectively [3-5]. Recurrent seizures can bring about a variety of physical, psychological, and social morbidities [6]. On the other hand, by complete control of the seizures, all these consequences are preventable which can be achieved by an optimal dose of antiepileptic medications [7]. However, a considerable proportion of patients with epilepsy suffer from drug-resistant-epilepsy (DRE) which affects $30 \%$ to $40 \%$ of adult epileptic patients [810].

A variety of definitions has been proposed for DRE in different periods which varied in different aspects including the number of failed antiepileptic drugs, seizure frequency, and temporal criteria (time duration for the occurrence of the determined number of seizures)[11]. Therefore, the International League Against Epilepsy (ILAE) in a broad consensus defined DRE as "failure of adequate trials of at least two tolerated, 
appropriately chosen and used antiepileptic drug schedules (whether as monotherapies or in combination) to achieve sustained seizure freedom" [12].

The prediction of the future development of DRE is still a great challenge in the setting of clinical practice. Previous studies have postulated some possible risk factors for developing DRE including younger onset age, symptomatic etiology, abnormal electroencephalography (EEG) findings, and neurological impairment or mental retardation at the time of diagnosis, high-frequency seizures [11]. However, the majority of these studies have been conducted in children [13-16]. Therefore, this study aimed to investigate the prevalence of DRE and its associated factors in adults with epilepsy.

\section{Methods}

In this case-control study, all patients aged over 12 years with an established diagnosis of epilepsy since at least one year before the admission who were admitted with seizure to the neurology ward of a tertiary care hospital were consecutively included from 20th March 2014 to 19th March 2020. Patients admitted with seizure due to secondary causes such as medication (three-cyclic antidepressants, tramadol, etc.), metabolic disorders, electrolytes disturbances, and those with pseudo-seizures were excluded from our study. Patients were classified into two groups of DRE and non-DRE groups based on the definition of DRE proposed by the ILAE consensus mentioned above [12]. Accordingly, the patients were classified as DRE group if they had seizures despite using at least two well-selected antiepileptic medications with appropriate doses. The non-DRE group were consisted of those who did not meet the definition of DRE but had seizures despite using one antiepileptic medication and were seizure-free for at least 3 months before their admission. The archived-files of the patients were retrospectively reviewed and the following data were extracted and recorded in a pre-prepared checklist. Demographic data including age and sex, history of diabetes, cerebrovascular accidents (CVA), and hypertension (HTN), seizure type, and cause. EEG of the patients was also retrospectively analyzed by an attending neurologist who was blind to the clinical data of patients and classified into two categories of normal/abnormal EEGs. Classification of the seizure type into generalized and partial and determination of seizure cause was conducted based on the history, physical examination, and EEG findings.

The study protocol was approved by the medical ethics committee of the (hided for peer review).

Statistical analyses were conducted by using IBM SPSS Statistics version 22 (SPSS Inc., Chicago, Illinois). The normal distribution of the variables was tested using the Kolmogorov-Smirnov test. Age was compared between groups using the independent t-test. Categorical data were compared using the Pearson chi-square test. Multivariable logistic regression was used to detect independently associated factors with the development of DRE. A p-value of less than 0.05 was considered statistically significant.

\section{Results}


A total of 473 patients were included, of which 20 patients had pseudoseizure and 17 patients were aged less than or equal to 12 years who were excluded from the study. Among 436 patients with confirmed epilepsy, 255 (58.5\%) were male and 181 (41.5\%) were female. The mean age was $36.1 \pm 18.3$ years, ranging from 13 to 88 years (Figure 1). In the studied patients, 272 patients (62.4\%) had impaired EEG and the remaining 164 patients (37.6\%) had normal EEG. 97 cases (22.2\%) had DRE (Table 1). 409 patients $(93.8 \%)$ had generalized epilepsy and 27 patients $(6.2 \%)$ had partial epilepsy. Among the etiologies of seizures, the most common cases were idiopathic $(53.9 \%)$ followed by vascular causes (22.5\%), and CP/developmental disorders (8.3\%) (Table 1).

Table 1

Evaluated characteristics of patients in two groups

\begin{tabular}{|c|c|c|c|c|c|}
\hline & & Total & Non-DRE & DRE & P-value \\
\hline Age (year) & & $36(18)$ & $37(19)$ & $34(16)$ & 0.188 \\
\hline \multirow[t]{2}{*}{ Sex } & Female & $181(41.5)$ & $139(41.0)$ & $42(43.3)$ & 0.686 \\
\hline & Male & $255(58.5)$ & $200(59.0)$ & $55(56.7)$ & \\
\hline \multirow[t]{2}{*}{ Seizure type } & Generalized & $409(93.8)$ & 316 (93.2) & $93(95.9)$ & 0.338 \\
\hline & Partial & $27(6.2)$ & $23(6.8)$ & $4(4.1)$ & \\
\hline \multirow[t]{3}{*}{ Medical history } & Hypertension & $50(11.5)$ & 45 (13.3) & $5(5.2)$ & 0.027 \\
\hline & Diabetes & $28(6.4)$ & $24(7.1)$ & $4(4.1)$ & 0.295 \\
\hline & CVA & $23(5.3)$ & $20(5.9)$ & $3(3.1)$ & 0.275 \\
\hline \multirow[t]{7}{*}{ Seizure cause } & Idiopathic & $239(54.8)$ & $187(55.2)$ & $52(53.6)$ & \multirow[t]{7}{*}{0.015} \\
\hline & Vascular & $98(22.5)$ & $87(25.7)$ & $11(11.3)$ & \\
\hline & Post traumatic/surgery & $18(4.1)$ & $12(3.5)$ & $6(6.2)$ & \\
\hline & MS/degenerative & $7(1.6)$ & $4(1.2)$ & $3(3.1)$ & \\
\hline & Poor compliance & $26(6.0)$ & $18(5.3)$ & $8(8.2)$ & \\
\hline & $\mathrm{CP} /$ developmental disorders & $36(8.3)$ & $23(6.8)$ & $13(13.4)$ & \\
\hline & Space occupying lesion & $12(2.8)$ & $8(2.4)$ & $4(4.1)$ & \\
\hline \multirow[t]{2}{*}{$E E G$} & Normal & $164(37.6)$ & $141(41.6)$ & $23(23.7)$ & 0.001 \\
\hline & Impaired & $272(62.4)$ & $198(58.4)$ & $74(76.3)$ & \\
\hline
\end{tabular}

There was no significant difference between DRE and non-DRE patients in terms of age, sex, seizure type (generalized/partial), and positive history of DM and CVA (Table 1). However, patients in the non-DRE group more frequently had HTN than the DRE group ( $13.3 \%$ vs $5.2 \%$-value $=0.027) .76 .3$ percent of the 
patients in the DRE group and 58.4 percent of non- DRE group had impaired EEG ( $p$-value $=0.001)$. The two groups of patients had a significant difference in the type of seizure causes. Vascular causes were more prevalent in the non-DRE group and idiopathic, post-traumatic/surgery, MS/degenerative, poor compliance, $\mathrm{CP} /$ developmental disorders, and space-occupying lesions were more prevalent in the DRE group (Figure 2). In multivariate regression analysis only the presence of $\mathrm{CP} /$ developmental disorders was independently associated with a higher probability of DRE (adjusted OR=2.170, $95 \% \mathrm{Cl}=1.017$ to 4.633, $p=0.045)$ (Table 2).

Table 2

Result of multivariate regression analysis in the prediction of drug-resistance epilepsy

\begin{tabular}{|c|c|c|c|c|c|}
\hline & & \multicolumn{4}{|c|}{$\begin{array}{l}95 \% \text { confidence } \\
\text { interval }\end{array}$} \\
\hline & & $\begin{array}{l}\text { Adjusted odds } \\
\text { ratio }\end{array}$ & Lower & Upper & $\begin{array}{l}P \text { - } \\
\text { value }\end{array}$ \\
\hline \multirow{7}{*}{$\begin{array}{l}\text { Seizure } \\
\text { cause }\end{array}$} & Idiopathic & Ref & - & - & 0.064 \\
\hline & Vascular & 0.454 & 0.183 & 1.124 & 0.088 \\
\hline & Post traumatic/surgery & 1.710 & 0.605 & 4.836 & 0.312 \\
\hline & MS/degenerative & 2.460 & 0.499 & 12.120 & 0.269 \\
\hline & Poor compliance & 1.540 & 0.628 & 3.777 & 0.346 \\
\hline & $\begin{array}{l}\text { CP/developmental } \\
\text { disorders }\end{array}$ & 2.170 & 1.017 & 4.633 & 0.045 \\
\hline & Space occupying lesion & 1.708 & 0.476 & 6.130 & 0.411 \\
\hline \multirow[t]{2}{*}{ Sex } & Female & 0.842 & 0.524 & 1.353 & 0.476 \\
\hline & Male & Ref & - & - & \\
\hline \multirow[t]{2}{*}{ Hypertension } & Yes & 0.479 & 0.144 & 1.595 & 0.230 \\
\hline & No & Ref & - & - & \\
\hline \multirow[t]{2}{*}{ Diabetes } & Yes & 1.142 & 0.312 & 4.185 & 0.841 \\
\hline & No & Ref & - & - & \\
\hline \multirow[t]{2}{*}{ CVA } & Yes & 1.080 & 0.263 & 4.437 & 0.915 \\
\hline & No & Ref & - & - & \\
\hline \multirow[t]{2}{*}{ Seizure type } & Generalized & 0.763 & 0.242 & 2.407 & 0.644 \\
\hline & Partial & Ref & - & - & \\
\hline
\end{tabular}




\section{Discussion}

Fair and poor seizure control are associated with a significantly lower quality of life and a higher prevalence of depression, anxiety, and stress in patients with epilepsy [17]. Also, DRE is reported to have serious physical and emotional consequences and it poses a great burden on the family as well as on social, educational, and health services [18]. Furthermore, these patients are at higher risk of some potentially life-threatening events, arising as a result of uncontrolled seizures including aspiration, electrolyte imbalance, brain edema, refractory status epilepticus, renal failure, cardiac arrhythmias, and unexplained sudden death [15]. It should be noted that the prevalence of DRE is considerably high. In the current study, $22 \%$ of adults with epilepsy admitted during six years had DRE. According to a systematic review and meta-analysis on 19 studies, the pooled incidence of DRE in epilepsy patients was 20\% (95\% $\mathrm{Cl} 14-27 \%$ ). Though there was a great heterogeneity among the included studies in this review (ranging from a prevalence of 6-51\%) [11]. Another systematic review and meta-analysis on 15 studies estimated that the prevalence of DRE is $25 \%(95 \% \mathrm{Cl} 17-32 \%)$ [19]. The heterogeneity among studies is partially due to the different DRE definitions. In the current study, we applied the most updated definition of DRE which was established by the consensus of ILAE [12]. In the systematic review by Kalilani et al. of 15 included studies, only 4 studies (10.5\%) used a case definition of DRE that complied with the ILAE definition of DRE [19]. Some investigators defined DRE with higher the number of failed antiepileptic medications [15, 20-23]. While other studies only required failure of one antiepileptic medication [24-26]. Furthermore, the discrepancy among different studies is attributable to the differences in the genetic/ethnicity predisposition [27]. As far as we investigated, our study is the first study on the Iranian population, evaluating the prevalence and associated factors of DRE in adults.

In the current study in a relatively large number of epileptic patients, we identified a positive history of $\mathrm{CP} /$ developmental disorders as an independently associated factor with DRE. However, age and sex were not associated with DRE. Likewise, Farghaly et al. by evaluation of 437 patients with epilepsy also reported that age and sex were not associated with DRE but mental retardation significantly increased the risk of DRE [26]. These results were in concordance with the results of Chawla et al. and Eriksson and Koivicco, who reported that perinatal problems were the leading cause of DRE $[28,29]$. The association of $\mathrm{CP} /$ developmental disorders with DRE may be attributed to the pathophysiology and brain structural abnormalities of these diseases. However, due to the intellectual disabilities of these patients, there is a possibility of a lack of adequate adherence to the prescribed antiepileptic medications. Therefore, first, perinatal care should receive more attention to reduce the possibility of developing these anomalies. Second, these patients should be encouraged and helped out to use their medications accurately.

Some studies postulated that the rate of partial epilepsy is significantly higher in DRE patients [26, 30, 31]. However, we did not find any significant association between seizure type and DRE. Similarly, Kalilani et al. by a meta-analysis of 15 studies data, failed to detect any significant relationship between seizure type and DRE [19]. However, it should be noted that the number of patients with partial seizure was 
relatively low in our study. This is because we conducted this study on the admitted patients and patients with partial seizures are rarely get admitted to the wards. Therefore, the results of our study on the relationship between seizure type and DRE may hardly generalizable for the whole population. Thus, it is warranted that this issue gets investigated in future population-based studies.

As like other retrospective studies, the main limitation of our study was the lack of recorded data ascertainment, which meant that the data on the cause of epilepsy could not be ascertained.

Nonetheless, the patients were admitted to a teaching hospital and were under observation by attending neurologists. Moreover, the number of used antiepileptic medications and characteristics of the seizures was recorded based on the patient's/components' claims.

\section{Conclusion}

The prevalence of DRE is still considerably high. Therefore, considering its serious consequences, more investigations should be carried out to determine proper strategies for reducing its incidence. We found the history of $\mathrm{CP} /$ developmental disorders to be independently associated with DRE. Therefore, regarding perinatal care to reduce the incidence of $\mathrm{CP} /$ developmental disorders and encouraging them to use their medications accurately can be helpful.

\section{Declarations}

\section{Ethics approval and consent to participate:}

The study was performed in accordance with the declaration of Helsinki. The protocol of this study was approved by the medical ethics committee of the Urmia University of Medical Sciences (IR.UMSU.REC.1396.125). Written informed consent was obtained from all participants.

\section{Consent for publication:}

Not applicable.

\section{Availability of data and materials:}

All Data and material collected during this study are available from the corresponding author upon reasonable request.

\section{Conflicts of interest/Competing interests:}

None declared. 


\section{Funding:}

This study was supported by the Urmia University of Medical Sciences.

\section{Authors' contributions:}

Conceptualization: PM, SN; Methodology: PM, SN; Formal analysis and investigation: SN; Writing (original draft preparation): PM, SN; Writing (review and editing): PM, SN; Funding acquisition: SN; Resources: PM, SN; Supervision: SN

\section{Acknowledgements:}

None.

\section{References}

1. Abramovici S, Bagić A. Epidemiology of epilepsy. Handbook of clinical neurology. 138: Elsevier; 2016. p. 159-71.

2. Ngugi AK, Bottomley C, Kleinschmidt I, Sander JW, Newton CR. Estimation of the burden of active and life-time epilepsy: a meta-analytic approach. Epilepsia. 2010;51(5):883-90.

3. Shakirullah AN, Khan A, Nabi M. The prevalence, incidence and etiology of epilepsy. Int J Clin Exp Neurol. 2014;2(2):29-39.

4. Noronha ALA, Borges MA, Marques LHN, Zanetta DMT, Fernandes PT, De Boer $\mathrm{H}$, et al. Prevalence and pattern of epilepsy treatment in different socioeconomic classes in Brazil. Epilepsia. 2007;48(5):880-5.

5. Banerjee PN, Filippi D, Hauser WA. The descriptive epidemiology of epilepsy-a review. Epilepsy research. 2009;85(1):31-45.

6. Devinsky O. Patients with refractory seizures. New England Journal of Medicine. 1999;340(20):156570.

7. McCagh J, Fisk JE, Baker GA. Epilepsy, psychosocial and cognitive functioning. Epilepsy research. 2009;86(1):1-14.

8. Annegers JF, Hauser WA, Elveback LR. Remission of seizures and relapse in patients with epilepsy. Epilepsia. 1979;20(6):729-37.

9. Cockerell OC, Sander J, Hart YM, Shorvon SD, Johnson AL. Remission of epilepsy: results from the National General Practice Study of Epilepsy. The Lancet. 1995;346(8968):140-4.

10. Kwan P, Brodie MJ. Early identification of refractory epilepsy. New England Journal of Medicine. 2000;342(5):314-9. 
11. Xue-Ping W, Hai-Jiao W, Li-Na Z, Xu D, Ling L. Risk factors for drug-resistant epilepsy: a systematic review and meta-analysis. Medicine. 2019;98(30).

12. Kwan P, Arzimanoglou A, Berg AT, Brodie MJ, Allen Hauser W, Mathern G, et al. Definition of drug resistant epilepsy: consensus proposal by the ad hoc Task Force of the ILAE Commission on Therapeutic Strategies. Epilepsia. 2010;51(6):1069-77.

13. Aaberg KM, Bakken IJ, Lossius MI, Søraas CL, Tallur KK, Stoltenberg C, et al. Short-term seizure outcomes in childhood epilepsy. Pediatrics. 2018;141(6).

14. Boonluksiri P, Visuthibhan A, Katanyuwong K. Clinical prediction rule of drug resistant epilepsy in children. Journal of epilepsy research. 2015;5(2):84.

15. Gururaj A, Sztriha L, Hertecant J, Eapen V. Clinical predictors of intractable childhood epilepsy. Journal of psychosomatic research. 2006;61(3):343-7.

16. Huang L, Li S, He D, Bao W, Li L. A predictive risk model for medical intractability in epilepsy. Epilepsy \& Behavior. 2014;37:282-6.

17. Hamid H, Blackmon K, Cong X, Dziura J, Atlas LY, Vickrey BG, et al. Mood, anxiety, and incomplete seizure control affect quality of life after epilepsy surgery. Neurology. 2014;82(10):887.

18. Manjunath R, Paradis PE, Parisé $H$, Lafeuille M-H, Bowers B, Duh MS, et al. Burden of uncontrolled epilepsy in patients requiring an emergency room visit or hospitalization. Neurology. 2012;79(18):1908-16.

19. Kalilani L, Sun X, Pelgrims B, Noack-Rink M, Villanueva V. The epidemiology of drug-resistant epilepsy: A systematic review and meta-analysis. Epilepsia. 2018;59(12):2179-93.

20. Malik MA, Hamid MH, Ahmed TM, Ali Q. Predictors of intractable childhood epilepsy. J Coll Physicians Surg Pak. 2008;18(3):158-62.

21. Berg AT, Levy SR, Novotny EJ, Shinnar S. Predictors of intractable epilepsy in childhood: a casecontrol study. Epilepsia. 1996;37(1):24-30.

22. Camfield P, Camfield C. The frequency of intractable seizures after stopping AEDs in seizure-free children with epilepsy. Neurology. 2005;64(6):973-5.

23. Casetta I, Granieri E, Monetti VC, Gilli G, Tole MR, Paolino E, et al. Early predictors of intractability in childhood epilepsy: a community-based case-control study in Copparo, Italy. Acta neurologica scandinavica. 1999;99(6):329-33.

24. Kun LN, Ling LW, Wah YW, Lian TT. Epidemiologic study of epilepsy in young Singaporean men. Epilepsia. 1999;40(10):1384-7.

25. Äikiä M, Kälviäinen R, Mervaala E, Riekkinen Sr PJ. Predictors of seizure outcome in newly diagnosed partial epilepsy: memory performance as a prognostic factor. Epilepsy research. 1999;37(2):159-67.

26. Farghaly WMA, El-Tallawy HN, Rageh TA, Mohamed EM, Metwally NA, Shehata GA, et al. Epidemiology of uncontrolled epilepsy in the Al-Kharga District, New Valley, Egypt. Seizure. 2013;22(8):611-6. 
27. Gregerson CHY, Bakian AV, Wilkes J, Knighton AJ, Nkoy F, Sweney M, et al. Disparities in Pediatric Epilepsy Remission Are Associated With Race and Ethnicity. Journal of Child Neurology. 2019;34(14):928-36.

28. Chawla S, Aneja S, Kashyap R, Mallika V. Etiology and clinical predictors of intractable epilepsy. Pediatric neurology. 2002;27(3):186-91.

29. Eriksson KJ, Koivikko MJ. Prevalence, classification, and severity of epilepsy and epileptic syndromes in children. Epilepsia. 1997;38(12):1275-82.

30. Kwong KL, Sung WY, Wong SN, So KT. Early predictors of medical intractability in childhood epilepsy. Pediatric neurology. 2003;29(1):46-52.

31. Singhvi JP, Sawhney IM, Lal V, Pathak A, Prabhakar S. Profile of intractable epilepsy in a tertiary referral center. Neurology India. 2000;48(4):351.

\section{Figures}

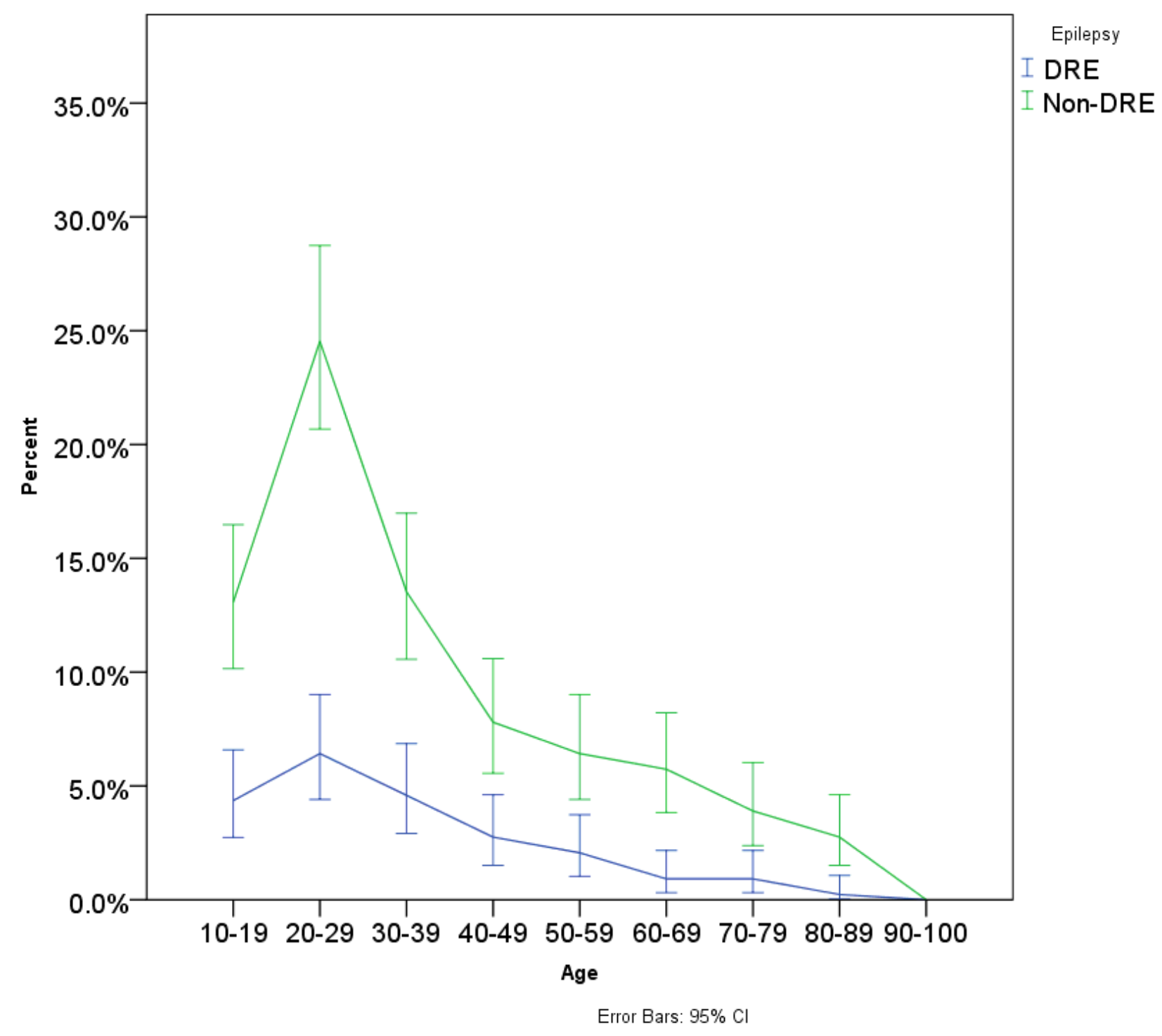


Age distribution in patients admitted with epilepsy in two groups of drug-resistant epilepsy (DRE) and non-DRE

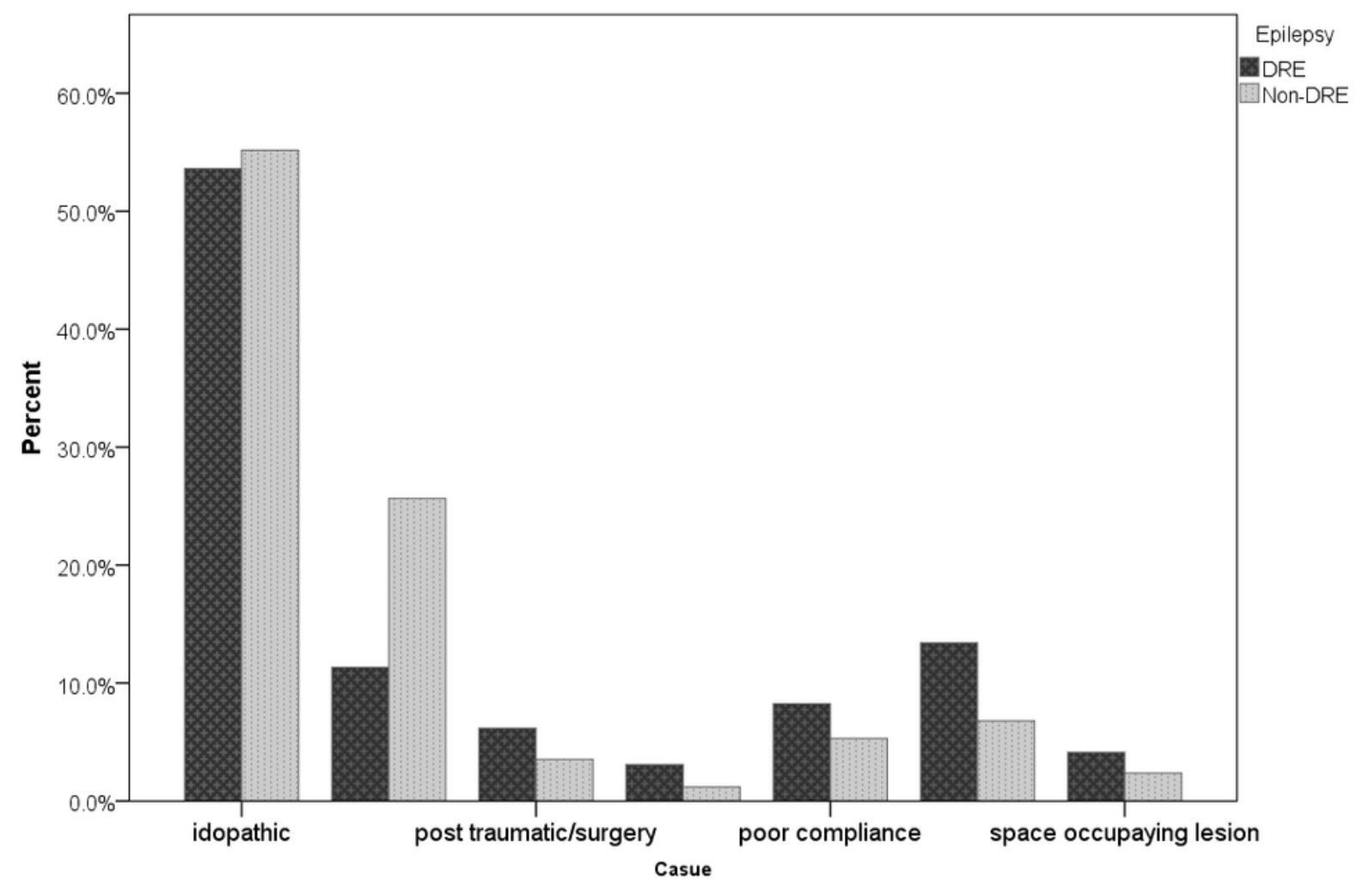

\section{Figure 2}

The proportion of drug-resistant epilepsy (DRE) in different causes of seizure 